\title{
Navigational Safety in SPM (Single Mooring Point) Regions
}

\author{
V. Paulauskas \\ Klaipeda University, Klaipeda, Lithuania
}

\begin{abstract}
For oil and gas transportation in some places used SPM (Single mooring point) system, this is located in the open sea and very often not so far away from the shore. Differences between the wind loads, waves and current forces can take a place. More complicate conditions can be in case if FSU is still in ballast and more influence has wind and waves as current and in the same time tanker in loaded position is more influenced by the current. Navigational safety ensure in SPM regions requests deep theoretical studies and very clear understanding of forces and moments, which influence on all the system (SPM, FSU, Tanker, tugs), practical implementation of proper equipment and use of correct methods of navigational safety. In this article there is made analysis of possible failures and necessary actions to ensure navigational safety in SPM regions.
\end{abstract}

\section{INTRODUCTION}

Navigational safety in SPM regions request deep theoretical studies and very clear understanding of forces and moments, which influence on all the system (SPM, FSU, Tanker, tugs), practical implementation of proper equipment and use of correct methods of navigational safety.

In case of FSU or tanker breakout (break towagemooring rope) between SPM and FSU or FSU and tanker, in case of bad weather conditions, wind, waves and current starts pushing FSU or tanker, or both in outer forces direction and if this direction will be to the shore or other navigational obstacles direction, just very fast and correct actions must be taken to solve problematic situation.

Tugs bollard pull is important for the ships, which are using SPM in open sea for the daily operation and especially for the emergency conditions (BS6349, 2003; EAU 2004, 2006). Typical emergency conditions are investigated in cases, when FSU or tanker has technical problems and is necessary to assist for the FSU or tanker in safety region. In different situations and additionally in case of use of FSU and tanker, hydro meteorologically conditions has different influence on FCU and tanker and it requests actions for preventing accidents or other failure problems.

\section{THEORETICAL BASIS OF THE NAVIGA- TIONAL SHIP'S HANDLING CONDITIONS}

Typical emergency conditions in SPM regions mainly are linked with:

- Main engine or rudder failure, weather from reasonable to good;

- FSU or tanker breakout during bad weather.

Mentioned conditions are very important, because SPM position is in open sea but very often close to navigational obstacles (shore and shallow waters) and it is very important to have correct and fast answers regarding requested bollard pull and time stopping drift tanker and possibilities towage tanker or FSU away from dangerous places.

Theoretical Study was using three the main methods: 
- Calculation method on basis Ship's Theory and Ship's handling in complicate conditions (V. Paulauskas, 1999);

- Simulation, used simulators, such as SimFlex Navigator (SimFlex Navigator Simulator, 2006);

- For the checking calculations and simulation results, to use experimental results from similar conditions, which take place on other real SPM places (SPM accidents investigation results, 2007).

Calculations were made by methodic, presented in references (V. Paulauskas, 1994; 1999 and 2004), and mainly were oriented on more complicate conditions, that means acting in one direction with some angles wind, current and waves, including shallow water effect.

Simulations were provided with equaling ships with recalculation to concrete planning ship in ballast and loaded and in same way on basis mass differences can made simulations and taken tugs forces (bollard pull).

Experimental results were taken from similar conditions, which were made by Author or from known references.

Constant wind component, as example, create forces, which can be calculate as follows (V. Paulauskas, 1999, 2004):

$F_{C}=0,5 \cdot C_{a} \cdot \rho_{1}\left(S_{x} \cdot \cos q_{a}+S_{y} \cdot \sin q_{a}\right) \cdot v_{a C}^{2}$

where:

- $C_{a}$ - aerodynamic coefficient, can be taken for such type calculations equal to 1 or can be taken for concrete ship, which model was tested in aerodynamic tube, data;

- $\rho_{1}$ - wind density, for the calculations can be taken as $1,25 \mathrm{~kg} / \mathrm{m}^{3}$;

- $S_{x}$ - wind surface area on diametric direction;

- $S_{y}$ - wind surface area on middle direction;

- $9_{a}^{y}$ - wind course angle;

- $v_{a C}$ - average wind velocity.

Periodical forces can be calculated via acceleration as follows:

$$
F_{p}=4 \cdot \pi^{2} \cdot t /\left(\tau^{2}\right) \cdot a \cdot \sin (2 \cdot \pi \cdot t / \tau)
$$

Finally periodical force can be expressed as follows:

$$
F_{P}=F_{P}^{\prime \prime} \cdot m,
$$

where:

- $m$-ship's mass;

- $\tau$ - period of wind guess;

- $a$ - integration constant, which can be find as: $a=0,25 \cdot C_{a} \cdot \rho_{1} \cdot \Delta v_{a}^{2}\left(S_{x} \cdot \cos q_{a}+S_{y} \cdot \sin q_{a}\right)$

Maximum forces, which can create periodical component of the wind, will be in case:

$\sin (2 \cdot \pi \cdot t / \tau)=1$

and maximum periodical forces will be in case:

$F_{P \max }=4 \cdot \pi^{2} \cdot t \cdot a \cdot m / \tau^{2}$

Waves constant and periodical forces can be calculate similar as wind loads as follows:

$F_{w c}=0,5 \cdot C_{w} \cdot \rho \cdot S_{x}^{\prime} \cdot v_{w}^{2} \cdot \cos q_{w}$,

where:

- $C_{w}$ - waves hydrodynamic coefficient, can be taken from $[1,2]$;

- $\rho$ - water density;

- $S_{w}$ - typical waves acting square;

- $v_{w}$ - waves spreading velocity;

- $q_{w}$ - waves course angle.

Waves periodical forces can be calculated similar as wind periodical forces, just in formulas (2) - (6) it is necessary to use wave's parameters.

\section{PRACTICAL REQUEST FORCES CALCULATIONS}

For the calculations is taken Suez Max tanker with next main dimensions: DWT - 183000 tons; length max - $274 \mathrm{~m}$; length between perpendiculars - 264 $\mathrm{m}$; width - $50 \mathrm{~m}$; height (board) - 23,1 m; draft - 17 $\mathrm{m}$ (loaded); draft $-8 \mathrm{~m}$ (in ballast).

Suez Max ship's other dimensions in ballast: wind area $S_{x}-4500 \mathrm{~m}^{2}$; wind area $S_{y}-1200 \mathrm{~m}^{2}$; underwater area $S_{x}^{\prime}-2100 \mathrm{~m}^{2}$; underwater area $S_{y}^{\prime} S^{\prime} y-400 \mathrm{~m}^{2}$.

Suez Max ship's dimensions loaded: wind area $S_{x}-2300 \mathrm{~m}^{2}$; wind area $S_{y}-800 \mathrm{~m}^{2}$; underwater area $S_{x}^{\prime}-4500 \mathrm{~m}^{2}$; underwater area $S_{y}^{\prime}-850 \mathrm{~m}^{2}$.

For the assistance were taken tugs with bollard pull $450 \mathrm{kN}$ and $650 \mathrm{kN}$ and were investigated FSU or tanker breakout during bad weather and Tanker main engine or rudder failure cases (Fig. 1). 


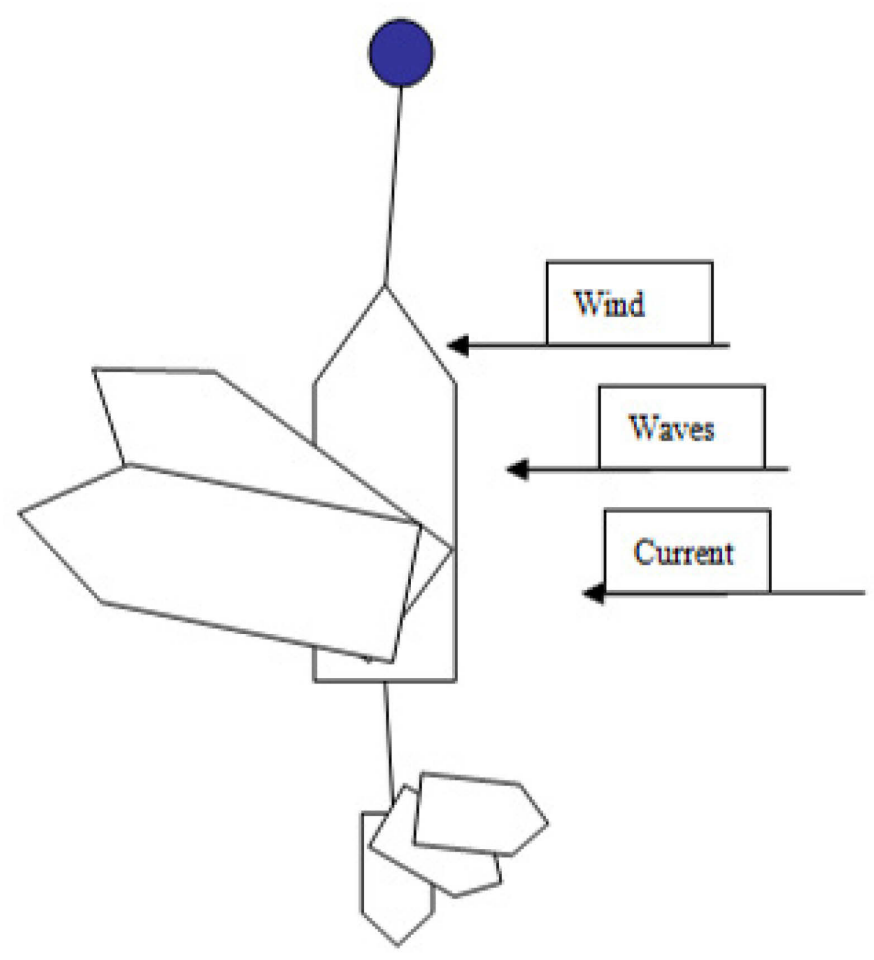

Figure 1. FSU or tanker breakout during bad weather.

Theoretical calculations results in case of acting wind and waves on loaded tanker are presented on table 1 and figure 2.

Table 1. Wind and waves forces on the Suez Max loaded tanker, forces in $\mathrm{T}$.

\begin{tabular}{lllll}
\hline $\begin{array}{l}\text { Wind } \\
\text { velocity, } \\
\mathrm{m} / \mathrm{s}\end{array}$ & $\begin{array}{l}\text { Wind and } \\
\text { waves } \\
\text { course } \\
\text { direction }\end{array}$ & $\begin{array}{l}\text { Wind and } \\
\text { waves } \\
\text { course } \\
\text { direction }\end{array}$ & $\begin{array}{l}\text { Wind and } \\
\text { waves } \\
\text { course } \\
\text { direction }\end{array}$ & $\begin{array}{l}\text { Wind and } \\
\text { waves } \\
\text { course } \\
\text { direction }\end{array}$ \\
\hline 5 & 1 & 2 & $30^{\circ}$ & $90^{\circ}$ \\
\hline 10 & 4 & 10 & 13 & 4 \\
15 & 11 & 26 & 32 & 15 \\
20 & 19 & 47 & 61 & 35 \\
25 & 30 & 77 & 102 & 115 \\
30 & 46 & 120 & 157 & 170 \\
\hline
\end{tabular}

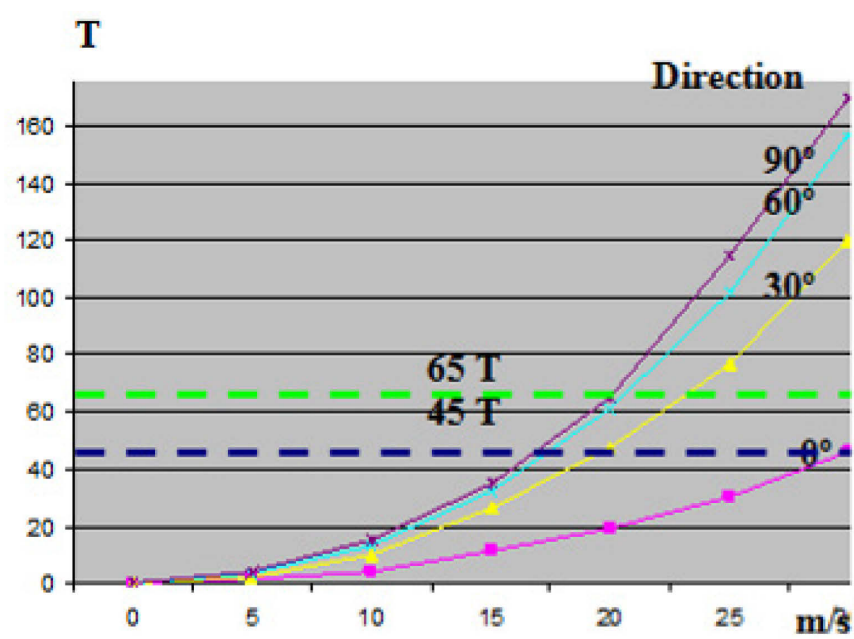

Figure 2. Wind and waves forces on the loaded Suez Max tanker depends on wind velocity and waves accordantly (wind and waves directions are the same)
In case of FSU or tanker breakout during bad weather, especially FSU, because normally tanker can not be moored to FSU during bad weather, very important to find weather limitations for the planned tugs. To turn loaded FSU or tanker, $65 \mathrm{~T}$ bollard pull tug has no limitations, $45 \mathrm{~T}$ bollard pull tug has limitations for the FSU or tanker in ballast: wind up to $18 \mathrm{~m} / \mathrm{s}$, waves up to $3,5 \mathrm{~m}$.

In case of FSU or tanker breakout (break towagemooring rope) between SPM and FSU or FSU and tanker, in case of bad weather, wind, waves and current start push FSU or tanker in acting forces direction and if this direction oriented to navigational obstacles, just very fast and correct actions must be taken to solve the problem. Tugs possibilities in case of loaded FSU or tanker are shown on fig. 2 (green line for $65 \mathrm{~T}$ bollard pull tug and blue line for tug 45 $\mathrm{T}$ bollard pull tug).

\section{REQUEST FOR NAVIGATIONAL REGION RECEIVED BY CALCULATIONS AND SIMULATOR TESTINGS}

Request for navigational region for the tankers maneuvering after breakout mooring rope in case tanker reach some drift speed received by theoretical calculations were checked by simulator and real data from SPM accident situations. All results were received very similar.

Simulations were made on visual simulator with possibility to simulate ship, tugs and sailing conditions. Simulations made for the emergency conditions, in case, when mooring rope has broken and tanker reached drift speed up to 4 knots before starting towage operation by tug. Simulations results for the loaded tanker drifting in first stage before tug started towage at the speed about 4 knots, presented on figure 3 by $65 \mathrm{~T}$ bollard pull tug and for the loaded tanker by $45 \mathrm{~T}$ bollard pull tug simulation results in the same conditions are shown on figure 4 and towage parameters for $45 \mathrm{~T}$ bollard pull tad are shown on figure 5 . 


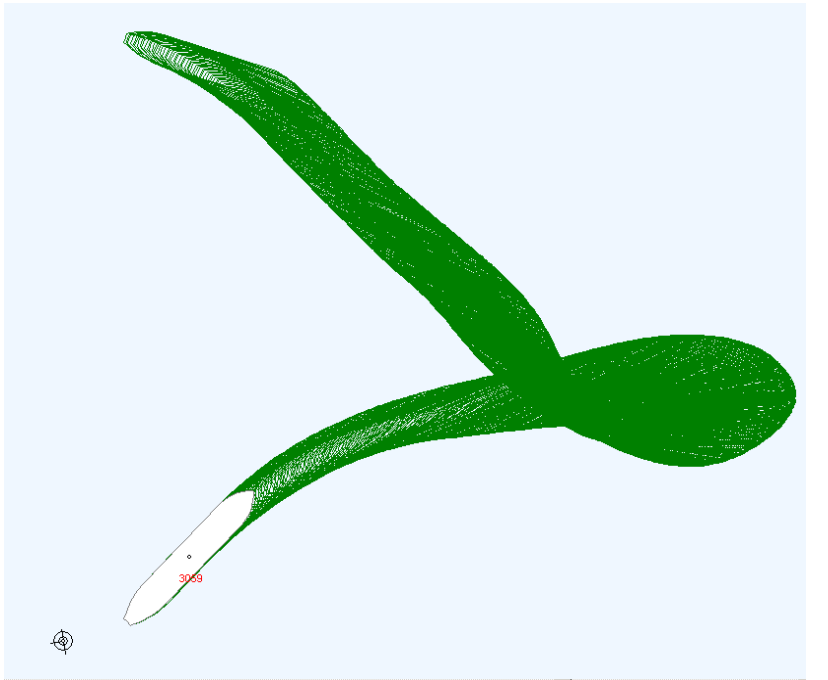

Figure 3. Loaded tanker and $65 \mathrm{~T}$ bollard pull tug way for the stopping and later towage tanker (before towage tanker drift speed reached 4 knots): wind $20 \mathrm{~m} / \mathrm{s}$; waves $4 \mathrm{~m}$, current 0,5 knots in to the same direction (to E).

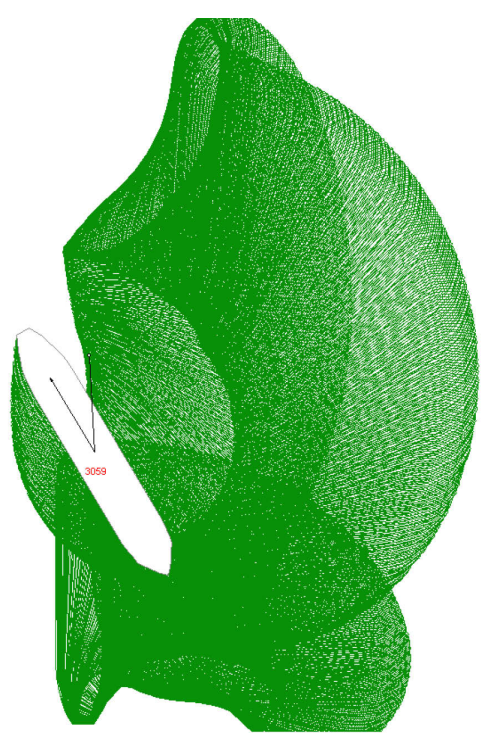

Figure 4. Loaded tanker and $45 \mathrm{~T}$ bollard pull tug way for the stopping and later towage tanker, on first tanker drift speed 1,5 knots: wind $20 \mathrm{~m} / \mathrm{s}$; waves $4 \mathrm{~m}$, current 0,5 knots in to the same direction (to $\mathrm{E}$ ).

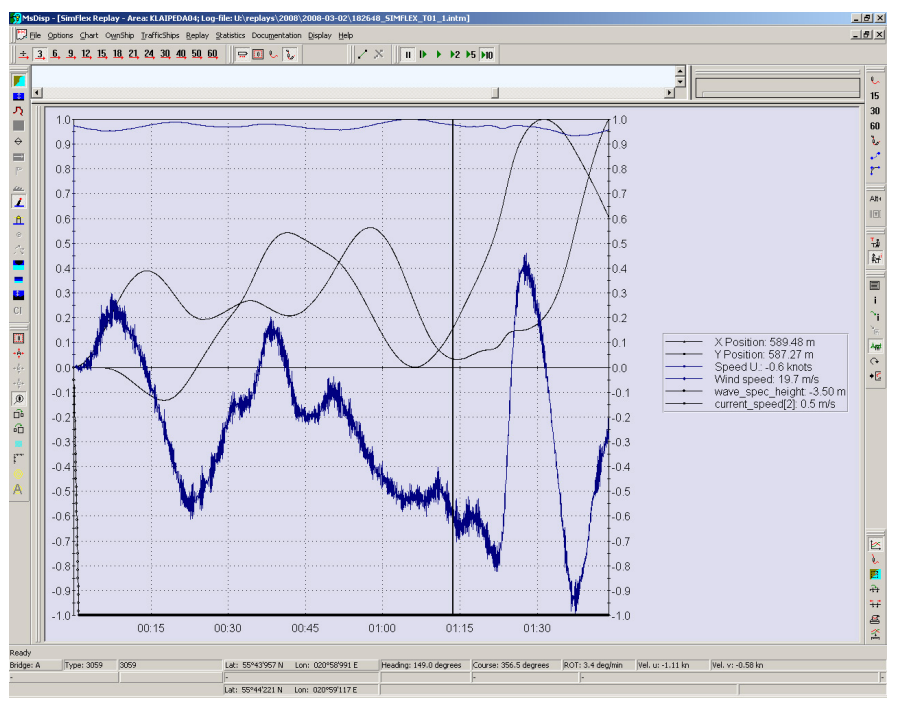

Figure 5. Loaded tanker and tug movement parameters: Time 00.00 - speed 1,5 knots; Tanker stopped by $45 \mathrm{~T}$ bollard pull tug and keep practically in the same place; Towage speed at the end of the process reaches $0,3 \mathrm{kn}$.

Calculation and simulation results were checked with available experimental (real) results in Butinge terminal (Lithuania), Petrol Baltic SPM (in Baltic Sea) and in other places in which used SPM. Correlation between calculation, simulation and experimental results are very good and it has shown that calculation methodology, prepared by author and explained in this paper, can be used on first stage for the forecasting situation to use SPM, request for navigational region, minimal tug's bollard pull and other details.

\section{CONCLUSIONS}

1 Methodology, presented in this paper can be used for the SPM conditions evaluation and forecasting requests for navigational region, tugs bollard pull, depends on tankers or FSU parameters.

2 Combination of the calculation methods, simulation possibilities on navigational simulators and checking by real data, could be the main way for receiving good quality results and for preparation of SPM work and emergency procedures.

3 In case of failure FSU or tanker engine or rudder system, strong enough tugs can take precautions measures in advance, stopping on navigational region tanker drifting or FSU and towage away from navigational dangerous places.

4 Theoretical methods are very important during planning of SPM and navigational regions around SPM, selection of the main elements in the region, such as minimal tug bollard pull, tugs maneuverability, ways in different conditions for the towage tanker or FSU away from navigational dangerous regions.

\section{REFERENCES}

1. BS 6349-1: 2000 - British Standard Maritime Structures Part 1: Code of Practice for General Criteria (British Standard Institution, July 2003)

2. EAU 2004 : Recommendations of the Committee for Waterfront Structures - Harbours and Waterways (Ernst \& Sohn, 2006)

3. Paulauskas V. 1994. Ship's steering. Klaipeda university publish house, Klaipeda, $164 \mathrm{p}$.

4. Paulauskas V.1999. Ship's steering in complicate conditions. Klaipeda university publish house, Klaipeda, $184 \mathrm{p}$.

5. Paulauskas V. 2004. Port terminals planning. Klaipeda university publish house, $382 \mathrm{p}$.

6. SimFlex Navigator Simulator, 2006. Force Technology, Denmark.

7. SPM accidents investigation results, 2007, (Butinge terminal). 